\title{
Formulation Development and Evaluation of Sustained Release Microsphere of Levetiracetam
}

Dinesh V. Panpaliya*, Atish Y. Sahare, Priyanka Lanje, Pooja Dhoke

Bajiraoji Karanjekar College of Pharmacy Sakoli Dist- Bhandara, Maharashtra, India.

*Corresponding author's E-mail: dineshpanpaliya91@gmail.com

Received: 20-09-2021; Revised: 16-11-2021; Accepted: 28-11-2021; Published on: 20-12-2021.

\section{ABSTRACT}

The aim of the present work was to develop and evaluate of oral microsphere of Levetiracetam to reduce the frequency of dosing by achieving 12 hours sustained drug release. The microsphere formed will also mask the bitter taste of the drug and thus increase the compatibility of the drug with the patients. Levetiracetam is a second-generation anti-epileptic agent useful in the treatment of partial onset and monoclinic seizures. It has a short half life of 7 hours and its recommended dose is $500 \mathrm{mg}$ twice a daily. Microspheres are suitable drug delivery system for such drug candidate. For these reasons it is must to formulate a suitable dosage form by which it will be easier to administer the dose and also to get a sustained drug release hence microsphere was prepared using solvent evaporation method. Preformulation studies were carried out to rule out any drug polymer interaction by FTIR technique. In this study formulation was done solvent evaporation method using different percentage of HPMC- K 100, HPMC- K 15 and coated with Eudragit S100. Drug, polymer and physical mixture were evaluated for in compatibility study by Fourier transforms infrared spectroscopy. All the batches of microsphere (F1 to F5) were subjected for in vitro dissolution. Microsphere was evaluated for surface morphology, micromeritics properties, entrapment efficiency and in vitro drug release. The entrapment efficiency of microsphere ranged from $71.16 \%-73.66 \%$. The size of the prepared microsphere ranges between $42.8 \mu \mathrm{m}$ to $55.64 \mu \mathrm{m}$ which was found to increase with increase in RPM at same polymer ratio. Micromeritics studies showed good flow properties. Among the microsphere batches, F5 was observed as an optimized batch as its formulation with polymer i.e. Eudragit-S 100 and HPMC-K 100 was found to be release in sustained manner. The F-5 batch shows is $79.45 \%$ drug release at the end of 7 hrs and its stability study indicate that these microspheres were stable at selected temperature and humidity while storage for 28 days without any significant changes in drug contents and drug release characteristics.

Keywords: Levetiracetam, Microsphere, HPMC K 100, HPMC K15, Eudragit S-100.

QUICK RESPONSE CODE $\rightarrow$

DOI:

10.47583/ijpsrr.2021.v71i02.026

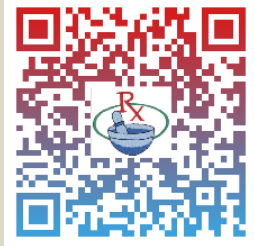

DOI link: http://dx.doi.org/10.47583/ijpsrr.2021.v71i02.026

\section{INTRODUCTION}

\section{evetiracetam}

(S)-a-ethyl-2-oxo-1-pyrrolidine acetamide is abroad-spectrum anti-epileptic drug that was approved by the U S Food and Drug Administration in 1999 and has quickly become one of the widely prescribed drugs for the treatment of partial and generalized epilepsy. While it is structurally unrelated to other anti-epileptic drugs, it is structurally related to nootropic agent piracetam. Levetiracetam is not considered a substrate for multi- drug transporters. ${ }^{1}$ Levetiracetam has novel mechanism of action involving an interaction with a novel binding site on the synaptic plasma membrane recently discovered to be the Synaptic Vesicle protein $2 \mathrm{~A} .^{2}$

In today's time there is a growing demand of sustained release drug delivery system. ${ }^{3}$ The population of patients with diseases such as epilepsy, hypertension and other chronic diseases has recently been increasing and such situations necessitate to take drug for a long period and/or multiple medicines simultaneously, which can lead to increase in non-compliance. The problem would be worse for drugs with short biological half-life. One method to solve such problem is to find a dosage form capable of releasing the drug gradually in a controlled manner. Epilepsy is a chronic neurological disorder affecting 40 million people worldwide and up to $30 \%$ of all seizures are provoked by CNS disorders. These seizures may become recurrent and require chronic treatment with antiepileptic drugs. Therefore, there is an ongoing need for new antiepileptic drug options without the limitations of multiple dosing. Epilepsy therapies with more convenient dosing schedules may help encourage greater patient compliance, which is important for effective seizure control. Levetiracetam is a second-generation antiepileptic drug for the treatment of partial onset and myoclonic seizures. According to Biopharmaceutics Classification System, Levetiracetam is type -1 drug which has high water solubility and permeability. The short halflife of the drug with bitter taste and a high dose of $500 \mathrm{mg}$ twice a daily makes it very incompatible for patients. Thus, by formulating a dosage form that could reduce the dosing frequency one could increase the patient compatibility. In the present research endeavor, levetiracetam oral microspheres were proposed to be developed to reduce

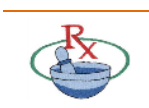


the frequency of dosing in addition to masking the bitter taste and faint odor. ${ }^{3}$

\section{MATERIALS AND METHODS}

\section{Materials}

Levetiracetam was received as a gift sample from Alembic Pharmaceuticals Mumbai. Eudragit S-100, Hydroxy Propyl Methyl Cellulose (HPMC) K 15 M and HPMC K 100 were received as gift samples from Colorcon Asia Ltd. (Goa, India). Ethanol, Dichloromethane, Liquid paraffin, $n-$ hexane and all other chemicals were purchased from S.D.Fine Chem. Ltd, Mumbai, India.

\section{Methods}

Levetiracetam Microsphere were prepared by dissolving polymer Eudragit -S 100, HPMC K 15 M and HPMC K 100 $M$ in ethanol and dichloromethane proportion mixture (2:1 ratio for F1-F3 and 2:1:1 for F4-F5). Then the drug levetiracetam was added to the polymer solution. The resulting mixture was then added drop by drop into heavy liquid paraffin while stirring continuously; stirring rate was constant at 900 RPM and continued for $2 \mathrm{hrs}$ until ethanol and dichloromethane solvent evaporated completely. The dispersed polymers were transferred into fine droplet, which subsequently solidified into rigid Microsphere due to solvent evaporation. The particles were collected by filtration and washed 4 to 5 times with $n$-Hexane and then after Microsphere dried $60^{\circ} \mathrm{C}$ for $3 \mathrm{Hr}$. the composition of Microsphere is given in table 1 .

\section{Formulation development of Levetiracetam microsphere}

Various Batches of microsphere formulation F1 to F5 for the drug levetiracetam were developed, as indicated in Table 1.

Table 1: Preparation of Levetiracetam Microsphere batches

\begin{tabular}{|c|c|c|c|c|c|c|c|c|}
\hline $\begin{array}{c}\text { Sr. } \\
\text { No. }\end{array}$ & Levetiracetam & $\begin{array}{c}\text { Eudragit-S } \\
100\end{array}$ & $\begin{array}{c}\text { HPMC } \\
\text { K 100M }\end{array}$ & $\begin{array}{c}\text { HPMC } \\
\text { K 15M }\end{array}$ & $\begin{array}{c}\text { Heavy } \\
\text { Liquid } \\
\text { Paraffin }\end{array}$ & Ethanol & $\begin{array}{c}\text { Dichloro- } \\
\text { methane }\end{array}$ & $\begin{array}{c}\text { RPM } \\
\text { Speed }\end{array}$ \\
\hline F1 & $500 \mathrm{mg}$ & $250 \mathrm{mg}$ & - & - & $50 \mathrm{ml}$ & $30 \mathrm{ml}$ & - & 900 \\
\hline F2 & $500 \mathrm{mg}$ & - & $250 \mathrm{mg}$ & - & $50 \mathrm{ml}$ & $15 \mathrm{ml}$ & $15 \mathrm{ml}$ & 900 \\
\hline F3 & $500 \mathrm{mg}$ & - & - & $250 \mathrm{mg}$ & $50 \mathrm{ml}$ & $15 \mathrm{ml}$ & $15 \mathrm{ml}$ & 900 \\
\hline F4 & $500 \mathrm{mg}$ & $250 \mathrm{mg}$ & - & $250 \mathrm{mg}$ & $50 \mathrm{ml}$ & $20 \mathrm{ml}$ & $20 \mathrm{ml}$ & 900 \\
\hline F5 & $500 \mathrm{mg}$ & $250 \mathrm{mg}$ & $250 \mathrm{mg}$ & - & $50 \mathrm{ml}$ & $20 \mathrm{ml}$ & $20 \mathrm{ml}$ & 900 \\
\hline
\end{tabular}

\section{Evaluation of the microsphere formulation}

The prepared microspheres were evaluated by following parameter:

\section{Preformulation}

The preformulation study was carried out to check the drug polymer compatibility. It was done using FTIR. Also, the UV spectrum was checked and calibration curve was plotted. FTIR spectra of levetiracetam, Eudragit S-100, HPMC K15 and HPMC K100 and Physical mixture of levetiracetam. IR spectrum was recorded using Perkin Elmer spectrum GX FT$\mathrm{IR}$, measured at maximum at $4000 \mathrm{~cm}^{-1}$ using Ethanol as blank.

\section{Percentage Yield ${ }^{4}$}

The yield of microspheres was determined by comparing the whole weight of microspheres formed against the combined weight of the copolymer and drug.

Percentage Yield $=\frac{\text { Mass of microspheres obtained }}{\text { Total weight of drug and polymer used }} \times 100$

\section{Particle Size and Shape ${ }^{5}$}

About 100 microspheres were randomly picked up thrice and their sizes of dried microspheres were measured by using Stage micrometer. Shape of microspheres was observed by visual observation.

\section{Micromeritic Studies}

The prepared microsphere is characterized by their micromeritics properties such as bulk density, tapped density, carr's compressibility index, Hausner's ratio and angle of repose.

\section{Bulk Density ${ }^{6}$}

For the determination of bulk density, weight quantities of microsphere were introduced into graduated measuring cylinder and were tapped mechanically or either manually till a constant volume was obtained. The bulk density of depends on particle size and distribution and particle shape. Bulk density is calculated by formula:

Bulk density $=\frac{\text { Mass of microsphere }}{\text { Bulk volume of microsphere }}$

\section{Tapped density}

Tapped density is the volume of powder determined by tapping by using a measuring cylinder containing weighed amount of sample. The measuring cylinder containing a know mass of microsphere were tapped for a fixed time, and the minimum volume occupied in the cylinder was measured. The tapped density was calculated by using the following formula

Tapped density $=\frac{\text { Mass of microsphere }}{\text { Volume of microsphere after tapping }}$ 


\section{Carr's compressibility index}

It is one of method for determining flow properties and also called as \% consolidation index. It is indirectly related to the relative flow rate, cohesiveness and particle size. It is simple, fast and popular method of predicting powder flow characteristic. This is an important property in maintaining uniform weight. It is calculated using following equation,

$\%$ compressibility index $=\frac{\text { tapped density-Bulk density }}{\text { Tapped density }} \times 100$

\section{Hausner ratio}

A similar index like percentage compressibility index has been defined by Hausner. Values less than 1.25 indicate good flow; whereas greater than 1.25 indicate poor flow. Added glidant normally improve flow of the material under study. Hausner ratio can be calculated by formula,

Hausner ratio $=\frac{\text { tapped density }}{\text { bulk density }}$

\section{Angle of Repose $(\theta)^{7}$}

Good flow property is critical for the development of any pharmaceutical tablet, capsules or powder formulation. It is essential that an accurate assessment of flow properties be made as early in the development process so that an optimum formulation can be quickly identified. Interparticle forces between particles as well as flow characteristics of powder are by angle of repose. Angle of repose is defined as the maximum angle possible between the surface and the horizontal plane.

The angle of repose of each powder blend was determined by glass funnel method. Powder was weighed accurately and passed freely through the funnel so as to form a heap. The height of funnel was so adjusted that the tip of the funnel just touched the apex of the heap. The diameter of the powder cone so formed was measured and angle of repose was calculated using the following equation.

$$
\begin{gathered}
\tan \theta=h / r \\
\theta=\tan ^{-1}(h / r)
\end{gathered}
$$

Where, $\theta=$ angle of repose

$$
\begin{aligned}
& h=\text { height of the pile and, } \\
& r=\text { radius of the powder cone respectively. }
\end{aligned}
$$

Angle of repose affect particle size distribution, as larger the particle size, it will flow freely and vice versa. It is helpful parameter to monitor quality of powdered or granular pharmaceutical formulation. For good flowing materials the angle of repose should be less than $30^{\circ}$

\section{Drug Entrapment Efficiency ${ }^{8}$}

Entrapment efficiency of microsphere was evaluated by deriving percent drug entrapment. The drug content of drug loaded microsphere was determined by dispersing 10 $\mathrm{mg}$ of microsphere in $10 \mathrm{ml}$ ethanol followed by agitation with magnetic stirrer for about 30 min to extract the drug and dissolved completely. After filtration through whatman filter paper the $1 \mathrm{ml}$ of this filtrate is pipette out and diluted up to the mark in $10 \mathrm{ml}$ volumetric flask. Drug concentration in ethanol phase was recorded by taking absorbance of this solution spectrophotometrically at $213 \mathrm{~nm}$. Finally total drug encapsulated in total yielded microsphere from the procedure was calculated. The amount of drug loaded and entrapped in the microsphere was calculated by the following formula.

$\%$ drug entrapment $=\frac{\text { amount of drug actually present }}{\text { theoretical drug load excepted }} \times 100$

\section{In vitro drug release study ${ }^{9}$}

A USP paddle apparatus was used to study in vitro drug release from microsphere. It is perform as per USP. In the present study, drug release was studied using a USP dissolution apparatus type 2 at 50-100 RPM phosphate buffer 7.4 as dissolution medium $(900 \mathrm{ml})$ maintained at $37 \pm 0.5^{\circ} \mathrm{C}$. with drawn samples $(5 \mathrm{ml})$ were analyzed spectrophotometrically at $213 \mathrm{~nm}$ shimadzu 1800 spectrophotometer. The volume was replenished with the same amount of fresh dissolution fluid each time to maintain the sink condition. The cumulative \% drug release was calculated and a graph of $\%$ cumulative drug release vs. time was plotted.

Details of dissolution testing is as follows,

- Apparatus :Electro lab

- Dissolution media: phosphate buffer 7.4

- $\quad$ Speed : 100 RPM

- Volume of medium : $900 \mathrm{ml}$

- Aliquots taken at each time intervals :5 ml

- Temperature : $37 \pm 0.5^{\circ} \mathrm{C}$

- Wavelength: $213 \mathrm{~nm}$

\section{Kinetic of Drug Release ${ }^{10,11}$}

In vitro dissolution has been recognized as an important element in drug development. To analysis the mechanism for the release and release rate kinetics of the formulated dosage form, the data obtained from conducted studies was fitted into zero order, first order, Higuchi matrix, korsmeyer-peppas and Hixson Crowell model. In this by comparing the $r$-values obtained, the best- fit model was selected.

\section{1) Zero order kinetics:-}

Drug dissolution from pharmaceutical dosage forms that do not disaggregate and release the drug slowly, assuming that the area does not change and no equilibrium condition is obtained can be represented by the following equation.

$Q_{t}=Q_{0}+K_{o} t$

Where, $Q_{t}=$ amount of drug dissolved in time $t$,

$$
\mathrm{Q}_{0}=\text { initial amount of drug in the solution and }
$$

$\mathrm{K}_{\mathrm{o}}=$ Zero order release constant 
This relation can be used to described the drug dissolution of several types of modified release pharmaceutical dosage forms, as in the case of some transdermal system as well as matrix tablet with low soluble drugs, coated form, osmotic system etc. The pharmaceutical dosage forms following this profile release the same amount of drug by unit of time and it is the ideal method of drug release in order to achieve a pharmacological prolonged action. To study the release kinetics, data obtained from in vitro drug release studies were plotted as cumulative amount of drug released vs time.

\section{2) First order kinetics:-}

To study the first order rate kinetics the release rate data were fitted to the following equation,

$\log Q_{t}=\log Q_{0}+K_{1} t / 2.303$

Where, $Q_{t}=$ amount of drug released in time $t$,

$$
\begin{aligned}
& \mathrm{Q}_{0}=\text { initial amount of drug in the solution and } \\
& \mathrm{K}_{1}=\text { first order release rate constant. }
\end{aligned}
$$

The pharmaceutical dosage forms following this dissolution profile such as those containing water-soluble drugs in porous matrices release the drug in a way that is proportional to the amount of drug remaining in its interior in such way that the amount of drug released by unit of time diminishes. The data obtained are plotted as log cumulative percentage of drug remaining versus time which would yield a straight line with a slope of $-K / 2.303$.

\section{3) Higuchi model:-}

Higuchi developed several theoretical models to study the release of water soluble and low soluble drugs in corporate in semisolids and or solid matrices. Mathematical expression was obtained for drug particles dispersed in a uniform matrix behaving as the diffusion media. To study the Higuchi model the release rate data were fitted to the following equation,

$$
Q_{t}=K_{H} t^{1 / 2}
$$

Where, $Q_{t}=$ amount of drug released in time $t$ and

$$
\mathrm{K}_{\mathrm{H}}=\text { Higuchi dissolution constant }
$$

Higuchi described drug release as a diffusion process based in the Fick's law, Square root time dependent. This relation can be used to describe the drug dissolution from several types of modified release pharmaceutical dosage forms, as in the case of some transdermal system and matrix tablet with water soluble drugs. The data obtained were plotted as cumulative percentage drug release versus square root of time.

\section{4) Korsmeyer-Peppas model:-}

To study this model the release rate data are fitted to the following equation,

$M t / M \infty=K \cdot t^{n}$

Where, $\mathrm{M}_{\mathrm{t}} / \mathrm{M}^{\infty}=$ fraction of drug released at time $\mathrm{t}$,

$$
\begin{aligned}
& \mathrm{K}=\text { release rate constant and } \\
& \mathrm{n}=\text { release exponent }
\end{aligned}
$$

In this model, the value of $\mathrm{n}$ characterizes the release mechanism of drug. For the case of cylindrical tablet, $0.45 \leq$ $\mathrm{n}$ corresponds to a fickian diffusion mechanism, $0.45 \leq \mathrm{n}<$ 0.89 to non-Fickian transport, $\mathrm{n}=0.89$ to case 2 (relaxational) transport, and $n>0.89$ to super case 2 transport. To find out the exponent of $\mathrm{n}$ the portion of the release curve, where $\mathrm{Mt} / \mathrm{M} \infty<0.6$ should only be used. To study the release kinetics, data obtained from in vitro drug release studies were plotted as log cumulative percentage drug release versus log time.

\section{5) Hixson - Crowell model:-}

To study the Hixson - Crowell model the release rate data are fitted to the following equation,

$\mathrm{K}_{\mathrm{s}} \mathrm{t}=\mathrm{W}_{\mathrm{o}}^{1 / 3}-\mathrm{W}_{\mathrm{t}}^{1 / 3}$

Where, $W_{0}=$ initial amount of drug in the pharmaceutical dosage forms,

$\mathrm{W}_{\mathrm{t}}$ = remaining amount of drug in the pharmaceutical dosage form at time $t$

$$
\mathrm{K}_{\mathrm{s}}=\text { constant incorporating the surface- volume }
$$
relation.

This expression applies to pharmaceutical dosage form such as tablet, where the dissolution occurs in planes that are parallel to the drug surface if the tablet dimension diminishes proportionally, in such a manner that the initial geometrical form keeps constant all the time. To study the release kinetics, data obtained from in vitro drug release studies were plotted as cube root of drug percentage remaining in matrix versus time.

\section{Stability studies ${ }^{12-14}$}

Stability of a drug has been defined as the ability of particular formulation, in a specific container, to remain within its physical, chemical, therapeutic and toxicological specifications. A drug formulation is said to be stable if it fulfils the following requirement:

- It should contain at least $90 \%$ of the stated active ingredient.

- It should contain effective concentration of added preservatives, if any

- It should not exhibit discoloration or precipitation, nor develops foul odour

- It should not develop irritation or toxicity.

- The purpose of stability testing is to provide evidence on how the quality of a drug substance or drug product varies with time under the influence of a variety of environmental factors such as temperature, humidity and light. International conference on Harmonization (ICH) specifies the length of study and storage conditions: 
Long term testing: $25^{\circ} \mathrm{C} \pm 2{ }^{\circ} \mathrm{C} / 60 \% \mathrm{RH} \pm 5 \%$ for 12 months.

Accelerated testing: $40^{\circ} \mathrm{C} \pm 2{ }^{\circ} \mathrm{C} / 75 \% \mathrm{RH} \pm 5 \%$ for 6 months.

In the present study, stability studies were carried out at $40^{\circ} \mathrm{C} \pm 2{ }^{\circ} \mathrm{C} / 75 \% \mathrm{RH} \pm 5 \%$ for a specific time period up to 28 days for the optimized formulation. The optimized formulation was analyzed for the drug entrapment efficiency and in vitro drug release study.

\section{RESULT AND DISCUSSION}

The present study has been a satisfactory attempt to formulate sustain release microsphere of Levetiracetam with a view of improving sustained release of the drug. From the experimental result it can be concluded that the various polymers were used for screening amongst then the microsphere prepared by Eudragit S 100, HPMC K 15M and HPMC K 100M shows good sphericity and particle size. Prior to formulate, preformulation studies were carried out in order to established compatibility between drug and polymer by FTIR spectroscopy. The result of FTIR study revealed that there is no physical or chemical interaction between drug and polymer. For the formulation biocompatible polymer Eudragit S 100, HPMC K 15M, HPMC $\mathrm{K} 100 \mathrm{M}$ were chosen in varying proportion with the drug. Solvent evaporation method was used to prepare microsphere employing ethanol and dichloromethane as solvent to dissolve the drug and the polymer.

\section{Preformulation Studies}

This study involved the calculation of calibration curve of the drug using a concentration range of $2-20 \mu \mathrm{g} / \mathrm{ml}$. The equation was $y=0.007 x$ with $R^{2}=0.996$. Also, the evaluation of compatibility of the drug with the different polymers of the formulation was conducted. The $\lambda$ max of the drug was found to be $213 \mathrm{~nm}$.

Graph 1: Standard Calibration curve of Levetiracetam in $\mathrm{pH}$ 7.4 buffer

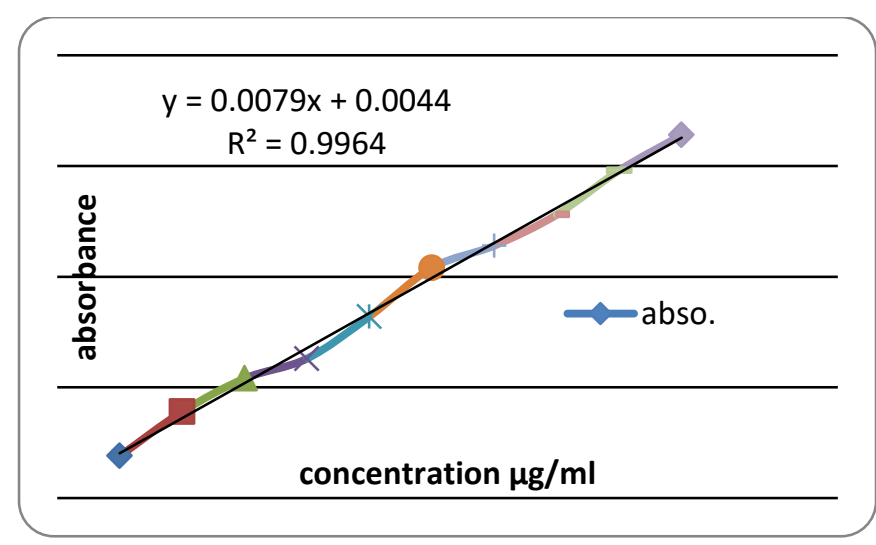

\section{Excipient Compatibility studies}

The Drug Excipient compatibility studies were conducted using FTIR instrument. It was observed that the characteristics drugs peaks were seen in the physical blend as well as in the formulation58. This signifies that the drug remains stable When formulated with mentioned Polymers.

\section{In Vitro drug release studies}

As shown (graph 8) the drug release from the formulation were affected by the polymer to the drug ratio. The batches F1- F3 which had drug to polymer ratio 2:1, gave F1-71.25\%, $\mathrm{F} 2-56.43 \%$ and $\mathrm{F} 3-63.19 \%$ drug release around $7 \mathrm{hrs}$. The composition batches F4-F5 with drug polymer ratio of 2:1:1 gave $\mathrm{F} 4-68.95 \%$ and $\mathrm{F} 5-79.45 \%$ drug release in $7 \mathrm{hrs}$ owing to their high drug to polymer ratio.

Table 2: Functional groups and their frequencies of Levetiracetam

\begin{tabular}{|c|c|c|}
\hline Groups & Reference Peak & Observed Peak \\
\hline$-\mathrm{O}-\mathrm{H}$ & $3600-3500$ & 3580.04 \\
\hline $\mathrm{N}-\mathrm{H}$ & $3400-3250$ & 3356.28 \\
\hline $\mathrm{N}-\mathrm{H}$ & $3400-3100$ & 3242.48 \\
\hline$-\mathrm{NO}_{2}$ & $1550-1380$ & 1448.60 \\
\hline $\mathrm{=}=\mathrm{O}$ & $1300-1000$ & 1089.83 \\
\hline
\end{tabular}

Graph 2: FTIR Spectrum of Levetiracetam Drug

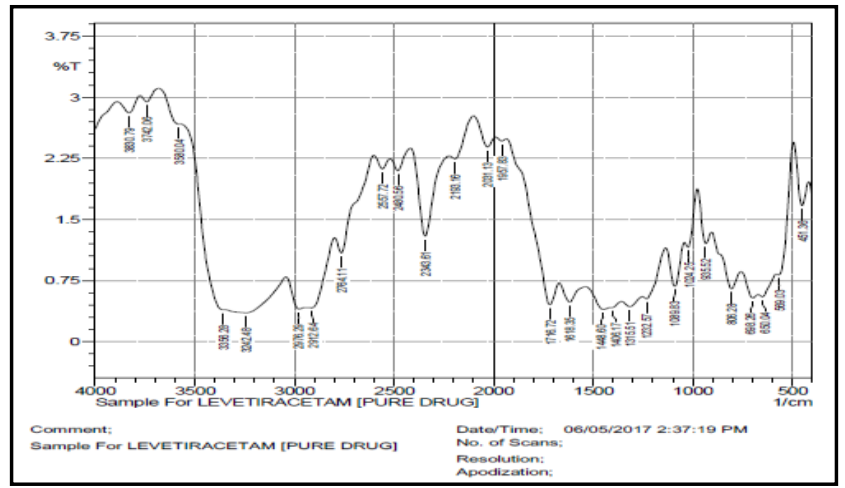

Table 3: Functional groups and their frequencies of HPMC K $15 \mathrm{M}$

\begin{tabular}{|c|c|c|}
\hline Groups & Reference Peak & Observed Peak \\
\hline$-\mathrm{O}-\mathrm{H}$ & $3550-3200$ & 3472.02 \\
\hline $\mathrm{C}=\mathrm{H}$ & $2850-3000$ & 2914.57 \\
\hline$-\mathrm{NO}_{2}$ & $1550-1380$ & 1450.53 \\
\hline =C-O- & $1300-1000$ & 1153.48 \\
\hline
\end{tabular}

Graph 3: FTIR spectrum of HPMC K 15M

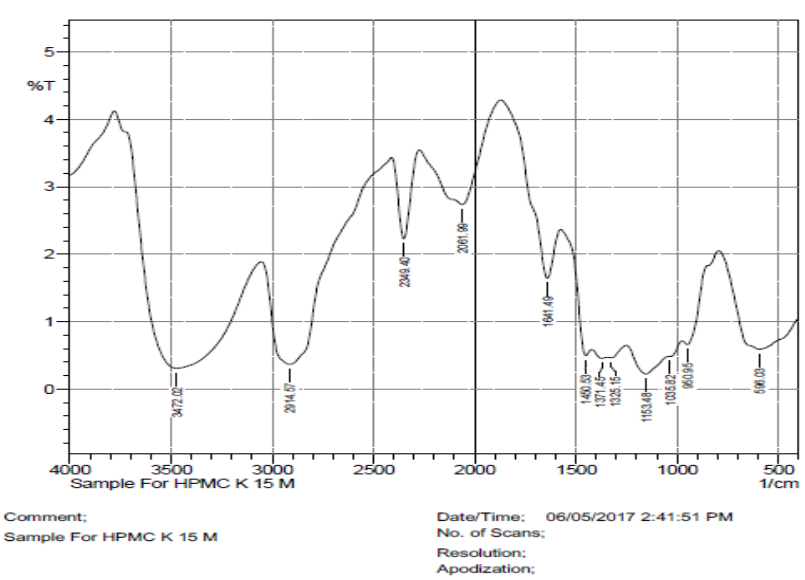


Table 4: Functional groups and their frequencies of HPMC K $100 \mathrm{M}$

\begin{tabular}{|l|c|c|}
\hline Groups & Reference Peak & Observed Peak \\
\hline$-\mathrm{O}-\mathrm{H}$ & $3550-3200$ & 3470.09 \\
\hline =C-H & $3000-28.50$ & 2914.57 \\
\hline$-\mathrm{NO}_{2}$ & $1550-1380$ & 1448.6 \\
\hline =C-O- & $1300-1000$ & 1157.34 \\
\hline
\end{tabular}

Graph 4: FTIR Spectrum of HPMC K 100M

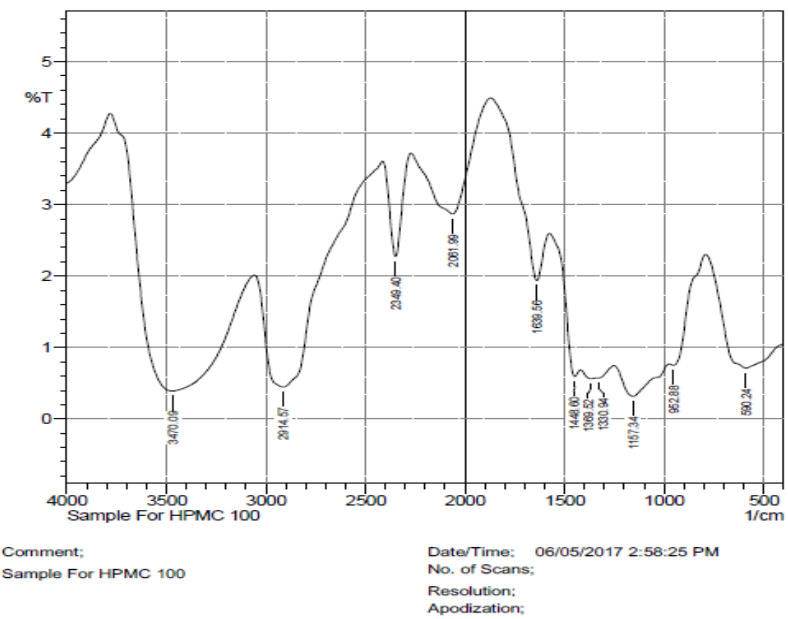

Table 5: Functional groups and their frequencies of Eudragit-S 100

\begin{tabular}{|l|c|c|}
\hline Groups & Reference Peak & Observed Peak \\
\hline$-\mathrm{O}-\mathrm{H}$ & $3550-3200$ & 3263.7 \\
\hline =C=H & $3000-2850$ & 2949.29 \\
\hline =C=O & $1850-1650$ & 1732.15 \\
\hline$-\mathrm{NO}_{2}$ & $1550-1380$ & 1381.09 \\
\hline =C-O- & $1300-1000$ & 1182.41 \\
\hline
\end{tabular}

Graph 5: FTIR Spectrum of Eudragit-S 100

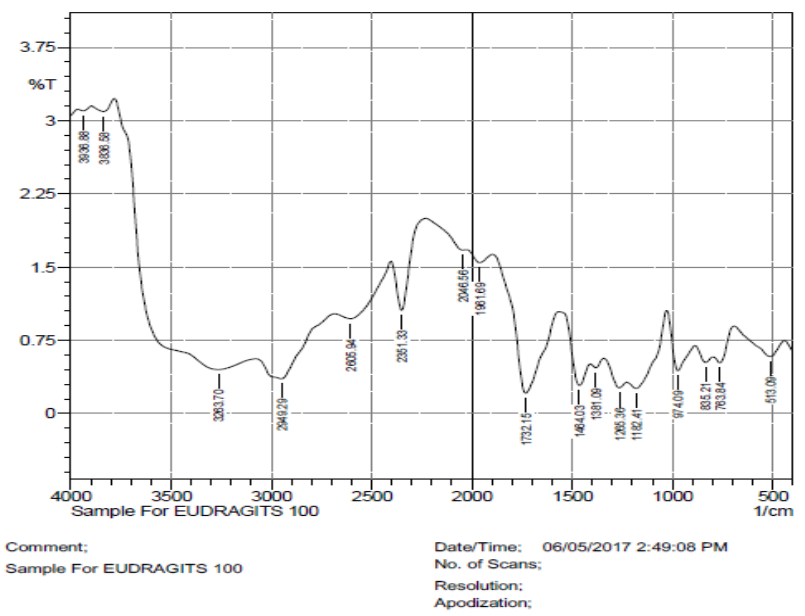

Table 6: Functional groups and their frequencies of levetiracetam, EudragitS-100, HPMC K 15 M

\begin{tabular}{|l|c|c|}
\hline Groups & Reference Peak & Observed Peak \\
\hline$-\mathrm{O}-\mathrm{H}$ & $3550-3200$ & 3362.07 \\
\hline $\mathrm{=}-\mathrm{N}-\mathrm{H}$ & $3400-3250$ & 3317.71 \\
\hline $\mathrm{=}=\mathrm{H}$ & $3000-2850$ & 2941.57 \\
\hline $\mathrm{=}=\mathrm{O}$ & $1820-1650$ & 1724.44 \\
\hline$-\mathrm{NO}_{2}$ & $1550 \& 1380$ & 1456.32 \\
\hline $\mathrm{=C}-\mathrm{O}-$ & $1300-1000$ & 1269.22 \\
\hline
\end{tabular}

Graph 6: FTIR Spectrum of Levetiracetam Drug, Eudragit- S 100, HPMC K 15M (Physical Mixture)

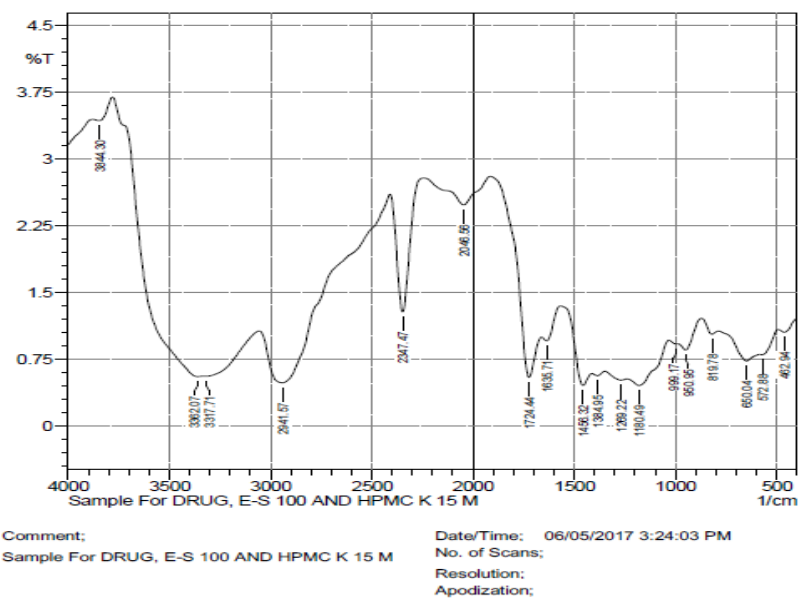

Table 7: Functional groups and their frequencies of levetiracetam, Eudragit S-100, HPMC K 100M

\begin{tabular}{|l|c|c|}
\hline Groups & Reference Peak & Observed Peak \\
\hline$-\mathrm{O}-\mathrm{H}$ & $3550-3200$ & 3360.14 \\
\hline $\mathrm{=}=\mathrm{C}$ & $3000-2850$ & 2935.78 \\
\hline $\mathrm{=}=\mathrm{O}$ & $1820-1680$ & 1720.58 \\
\hline $\mathrm{=}=\mathrm{C}=$ & $1660-1640$ & 1641.49 \\
\hline$-\mathrm{NO}_{2}$ & $1550 \& 1380$ & 1456.32 \\
\hline =C-O- & $1300-1000$ & 1269.22 \\
\hline
\end{tabular}

Graph 7: FTIR Spectrum of Levetiracetam drug + Eudragit S $100+$ HPMC K $100 M$

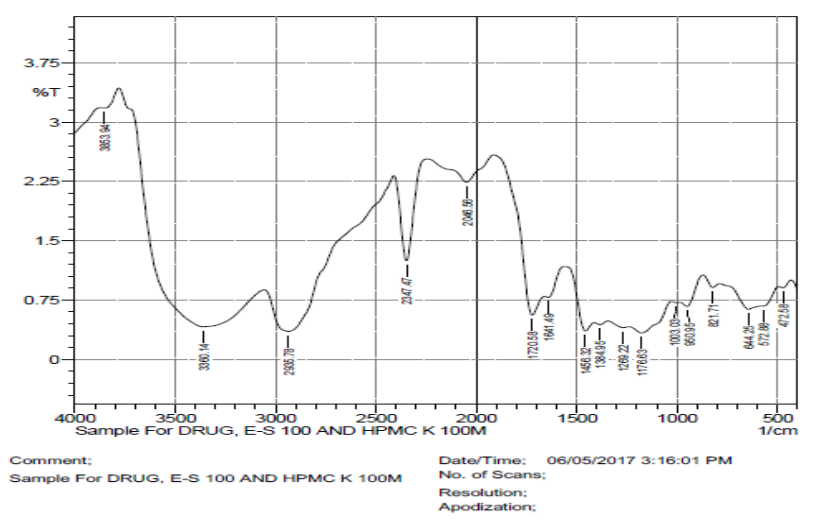


Table 8: Evaluation parameter of levetiracetam microsphere

\begin{tabular}{|c|c|c|c|}
\hline Batch & Mean Particle size (um) & Percentage yield (\%) & Entrapment efficiency (\%) \\
\hline F1 & 42.8 & $80.5 \%$ & $71.16 \%$ \\
\hline F2 & 55.64 & $83 \%$ & $68.28 \%$ \\
\hline F3 & 47.08 & $84.5 \%$ & $70.41 \%$ \\
\hline F4 & 51.36 & $88 \%$ & $69.03 \%$ \\
\hline F5 & 55.64 & $89.6 \%$ & $73.66 \%$ \\
\hline
\end{tabular}

Table 9: Flow properties of levetiracetam microsphere

\begin{tabular}{|l|c|c|c|c|c|}
\hline Batches & $\begin{array}{c}\text { Bulk density } \\
\text { (g/cc) }\end{array}$ & $\begin{array}{c}\text { Tapped density } \\
\text { (g/cc) }\end{array}$ & $\begin{array}{c}\text { Carr's compressibility } \\
\text { (\%) }\end{array}$ & Hausner's Ratio & Angle of Repose \\
\hline F1 & 0.423 & 0.473 & 10.57 & 1.11 & $24.54^{\circ}$ \\
\hline F2 & 0.425 & 0.474 & 10.33 & 1.11 & $24.50^{\circ}$ \\
\hline F3 & 0.422 & 0.469 & 10.02 & 1.11 & $24.34^{\circ}$ \\
\hline F4 & 0.538 & 0.643 & 16.32 & 1.19 & $28.54^{\circ}$ \\
\hline F5 & 0.542 & 0.646 & 16.09 & 1.19 & $28.56^{\circ}$ \\
\hline
\end{tabular}

Table 10: In vitro release study comparison of Levetiracetam Microsphere formulation

Batches F1, F2, F3, F4 and F5 for more \% Cumulative Drug Release.

\begin{tabular}{|c|c|c|c|c|c|}
\hline Time in hr & \%CDR F1 & \%CDR F2 & \%CDR F3 & \%CDR F4 & \%CDR F5 \\
\hline 0 & 0 & 0 & 0 & 0 & 0 \\
\hline 1 & 32.74 & 15.49 & 18.99 & 20.48 & 22.24 \\
\hline 2 & 42.53 & 29.75 & 29.75 & 30.51 & 30.51 \\
\hline 3 & 47.03 & 34.25 & 35.51 & 38.75 & 38.50 \\
\hline 4 & 54.56 & 40.54 & 42.3 & 47.30 & 46.80 \\
\hline 5 & 59.62 & 46.33 & 47.34 & 53.09 & 56.35 \\
\hline 6 & 65.68 & 51.37 & 54.87 & 60.65 & 68.89 \\
\hline 7 & 71.25 & 56.43 & 63.19 & 68.95 & 79.45 \\
\hline
\end{tabular}

Graph 8: Plot of time Vs \% Cumulative Drug Release Levetiracetam microsphere Formulation Batches F1, F2, F3, F4 and F5

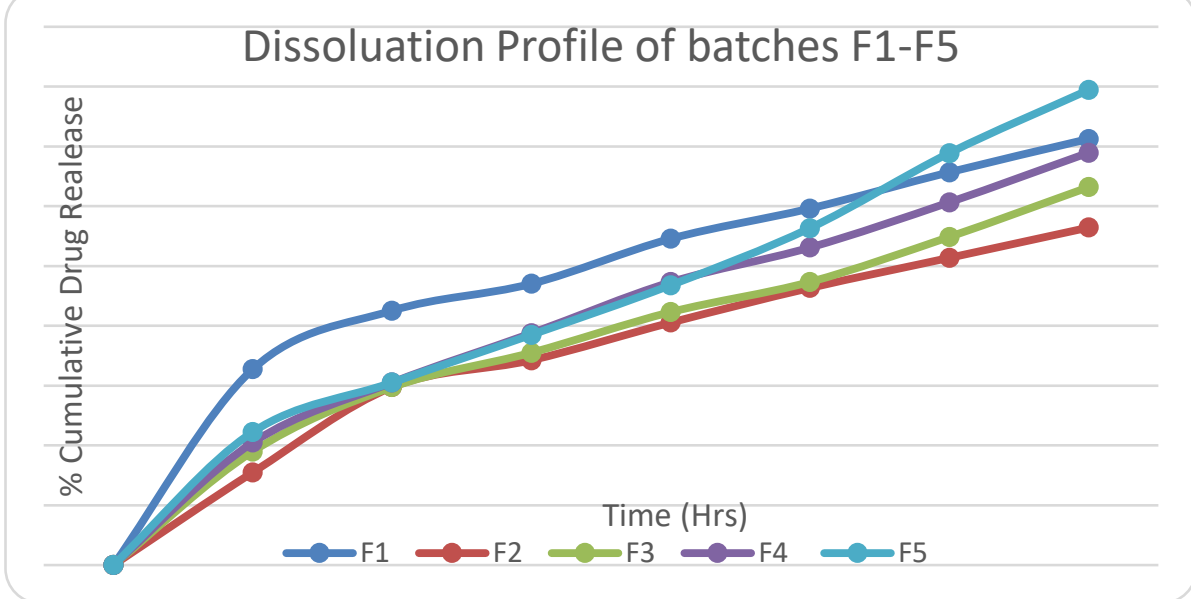

From the above result, the drug release of formulation batches F1-F5 was found to be $71.25 \%, 56.43 \%, 63.19 \%, 68.95 \%$ and $79.45 \%$ respectively. 
Kinetic of Drug Release: -

Table 11: Model Fitting Profile of Levetiracetam Sustained Release Microsphere F1-F5 Batch.

\begin{tabular}{|c|c|c|c|c|c|c|c|}
\hline \multirow{3}{*}{$\begin{array}{l}\text { Formulation } \\
\text { Batches }\end{array}$} & \multicolumn{6}{|c|}{ Mathematical Models (Kinetics) } & \multirow[t]{3}{*}{ Best fit model } \\
\hline & \multirow{2}{*}{$\begin{array}{c}\text { Zero } \\
\text { order } \\
\text { R }\end{array}$} & \multirow{2}{*}{$\begin{array}{c}\text { First order } \\
\text { R }\end{array}$} & \multirow{2}{*}{$\begin{array}{c}\text { Higuchi model } \\
\text { R }\end{array}$} & \multicolumn{2}{|c|}{$\begin{array}{c}\text { Korsmeyer } \\
\text { Peppas }\end{array}$} & \multirow{2}{*}{$\begin{array}{c}\text { Hixson } \\
\text { Crowell } \\
\mathbf{R}\end{array}$} & \\
\hline & & & & $\mathbf{R}$ & $\mathbf{N}$ & & \\
\hline $\mathrm{F} 1$ & 0.899 & 0.906 & 0.995 & 0.935 & 0.935 & 0.904 & Higuchi model \\
\hline $\mathrm{F} 2$ & 0.960 & 0.963 & 0.993 & 0.949 & 0.894 & 0.962 & Higuchi model \\
\hline F3 & 0.968 & 0.963 & 0.993 & 0.996 & 0.894 & 0.962 & Higuchi model \\
\hline $\mathrm{F} 4$ & 0.973 & 0.977 & 0.991 & 0.988 & 1.005 & 0.976 & Higuchi model \\
\hline F5 & 0.986 & 0.989 & 0.976 & 0.998 & 0.911 & 0.988 & Korsmeyer Peppas \\
\hline
\end{tabular}

The curve fitting result of the release rate profile of the designed formulation F1 to F5, which gives an idea on the release rate and the mechanism of release. The values were compared with each other for model and as shown in table 11 based on the highest regression value(r). Fitting of the release rate data to the various model revealed that the formulation F1, F2 and F3 are suitable with Higuchi Model and F5 is suitable with Korsmeyer Peppas.

\section{Stability Study}

The stability studies of optimum formulation revealed that there is slightly reduction in drug content was observed over period of 28 days. No significant change was observed at $40 \pm 2^{\circ}, 75 \% \mathrm{RH}$ hence formulation $\mathrm{F} 5$ was found to be stable for 28 days.

Table 12: Stability study

\begin{tabular}{|c|c|}
\hline Stability $\left(\mathbf{4 0} \pm \mathbf{2}^{\circ} \mathbf{C}\right)$ & Drug content (\%) \\
\hline 0 day & 81.17 \\
\hline 1 week & 81.03 \\
\hline 2 weeks & 80.95 \\
\hline 3 weeks & 80.87 \\
\hline 4 weeks & 80.83 \\
\hline
\end{tabular}

\section{CONCLUSION}

The prepared formulation was characterized for their percentage yield, micromeritics properties, particle size, drug entrapment and in-vitro drug release studies. Almost all the formulation showed fairly acceptable values for all parameter evaluated. Microsphere of different sizes and improved drug entrapment efficiency would be obtained by varying the drug to polymer ratio. The formulation showed good flow properties. Formulated microsphere was stable at the selected temperature and humidity in storage for 28 days. From the stability studies it was found that there was no significant change in the drug content and release characteristics. Hence, finally it was concluded that the prepared microsphere of Levetiracetam are sustained release. The F5 formulation may be the potential candidates for safe and effective sustained drug delivery over an extended period of time with reduce dosing frequency.

\section{REFERENCES}

1. Deshpande LS, DeLorenzo RJ. Mechanisms of levetiracetam in the control of status epilepticus and epilepsy. Frontiers in neurology, 2014; 5:11. doi: 10.3389/fneur.2014.00011.

2. Sendrowski K, Sobaniec W. New antiepileptic drugs - an overview. Roczniki Akademii Medycznej w Białymstoku, 2005; 50 (Suppl. 1): 96-98.

3. Banerjee $\mathrm{N}$, Singh S. Formulation, Evaluation and optimization of effervescent granules to be reconstituted into suspension of levetiracetam for sustained Release. International Journal of Pharmaceutical Science Reviews and Research, 2013; 20(2):181-186.

4. Balaiah A, Babu GE, Vijayalakshmi P, Raju KN, Deepika B. Formulation, development and in-vitro characterization of oral levetiracetam microsphere. International Research Journal of Pharmaceutical and Applied Science, 2012; 2(3):13-21.

5. Lakshmana Prabu S, Shirwaikar AA, Shirwaikar A, Kumar A. Formulation and evaluation of sustained release microspheres of rosin containing aceclofenac. Ars Pharm, 2009; 50(2):51-62.

6. Patil $P$, Singh $S$, Sarvanan J. Preparation and evaluation of microspheres of flurbiprofen. International Journal of Pharmaceutical Sciences and Research, 2018; 9(12): 53885393. Doi: 10.13040/IJPSR.0975-8232.9(12).5388-93.

7. Sharma A, Batra SK. Atenolol microparticles by two-factor two-level central composite design. Asian Journal of Pharmaceutical and Clinical Research, 2020; 13(4):192-201. doi: https://doi.org/10.22159/ajpcr.2020.v13i4.36467

8. Dangi AA, Ganure LA, Jain D. Formulation and evaluation of colon targeted drug delivery system of levetiracetam using pectin as polymeric carrier. Journal of Applied Pharmaceutical Science, 2013; 3(01):078-087. doi: 10.7324/JAPS.2013.30115

9. Phutane $P$, Shidhaye S, Lotlikar V, Ghule A, Sutar S, Kadam V. In vitro evaluation of novel sustained release microspheres of glipizide prepared by the emulsion solvent diffusionevaporation method. Journal of Young Pharmacists. 2010; 2(1): 35-41. doi: 10.4103/0975-1483.62210. 
10. Khan MS, Gowda DV, Bathool A. Formulation and characterization of piroxicam floating microsphere for prolonged gastric retension. Der Pharmacia Lettre, 2010; 2 (6):217-22.

11. Costa $P$, Lobo JMS. Modeling and comparison of dissolution profile. Eur J Pharm Sci, 2001; 13(2):123-133. doi: 10.1016/S0928-0987(01)00095-1.

12. Dash S, Murthy PN, Nath L, Chowdhary P. Kinetic modeling on drug release from controlled drug delivery system. Drug Research, 2010; 67(3):217-223.
13. Lachman L, Liberman HA, Kanig JL. Kinetic principles and stability. Theory and practice of industrial pharmacy. Varghese publishing house, Philadelphia, Third edition, 1986, p. $760-803$.

14. ICH Q1A (R2), Stability testing guidelines: stability testing of new drug substances and product, The European agency for the evaluation of medicinal product, $\mathrm{CPMP} / \mathrm{ICH} 2736 / 99$, 2003, p. 4-20.

Source of Support: The author(s) received no financial support for the research, authorship, and/or publication of this article.

Conflict of Interest: The author(s) declared no potential conflicts of interest with respect to the research, authorship, and/or publication of this article.

For any question relates to this article, please reach us at: editor@globalresearchonline.net New manuscripts for publication can be submitted at: submit@globalresearchonline.net and submit_ijpsrr@rediffmail.com 